\title{
Supervisory skills training for the neglected supervisors: Development and preliminary evaluation of an autonomy-supportive programme.
}

\begin{abstract}
Purpose - Previous studies have demonstrated that an autonomy-supportive supervision style is associated with improved well-being and positive behaviours for supervisees. However, autonomy-supportive training (AST) has yet to be tailored to suit supervisors in low-skilled occupations for whom traditional pedagogical approaches may be inappropriate. This article describes the development and preliminary evaluation of AST for these supervisors, using selfdetermination theory (SDT) and andragogical principles of adult learning.
\end{abstract}

Design/methodology/approach - SDT and andragogical principles were systematically integrated to develop (a three-hour) AST programme. The training sessions were trialled with 11 first-line supervisors in New Zealand as a preliminary evaluation of AST. The evaluation used open-ended questions following Kirkpatrick's evaluation model and incorporated the trainer's reflections.

Findings - Supervisors found AST relevant, easy to understand, and suited to their approach to learning. Trainer's reflections also provided insight into the challenges in conducting such training for supervisors in low-skilled occupations and the article makes suggestions to address these challenges.

Research implications/limitations - AST can be successfully tailored to first-line supervisors, indicating that an autonomy-supportive style of leadership is relevant for those employed in low- 
skilled occupations. This initial evaluation provides a foundation for future studies to conduct higher-level assessment of AST.

Practical implications - AST can be utilised to provide first-line supervisors with access to improved leadership development opportunities. Challenges of conducting this kind of training programme in a context of low-skilled occupations are addressed and recommendations made for organizations and trainers.

Originality/value - This study is novel as it demonstrates the development of AST, a leadership skills training, tailored to suit the needs of an understudied group, supervisors in low-skilled occupations.

Keywords Leadership skills training, Autonomy-supportive style, Andragogy, Low-skilled occupations

Paper type Research paper

\section{Introduction}

Formal workplace training is one of the components of lifelong learning and skill development. For employees in low-skilled occupations, learning is often perceived as formal learning activity such as attending a training session (Kyndt et al., 2013). However, opportunities for such training are not equal for all employees and those in low-skilled occupations especially may be excluded, as the nature of these jobs requires minimal education and sometimes does not provide a conducive environment for learning (Payne, 2006). As employees in low-skilled occupations move up the ranks and take on supervisory roles, attaining 
leadership skills becomes important, yet nearly half of businesses promote supervisors based on their task performance rather than leadership or people management skills (Lawrence, 2013). Supervisors require leadership skills in order to contribute to better organisational performance (Pederson et al., 2013, Purcell and Hutchinson, 2006) but are rarely given formal training and feedback (Teague and Roche, 2012). A survey of the manufacturing sector indicated that this lack of people management skills is a particular problem in New Zealand, which was ranked only 14 out of the 17 countries (Green et al., 2011). The survey also indicated that manufacturing industries in New Zealand fare particularly badly with issues such as addressing poor performance, retaining high performers and promoting high performers. This further highlights the need for leadership skills training for supervisors.

According to self-determination theory (SDT), an autonomy-supportive supervisory style could result in better work performance, and it does so by satisfying the basic needs of autonomy, competence and relatedness of employees (Deci et al., 2017). A recent meta-analysis by Slemp et al. (2018) has found that autonomy-supportive supervision contributes to employees' well-being and positive behaviours at work. Autonomy-supportive supervisory style not only benefits the recipients (employees) but also those who practise it (supervisors) by satisfying their basic psychological needs as well (Reeve and Cheon, 2014).

Autonomy-supportive supervisory style encompasses skills such as providing meaningful reasoning for a task, taking employees’ perspective, minimising controlling language such as “should" or "must" and supporting employees to be self-determining (Su and Reeve, 2011). Organizational studies have shown that supervisors can be trained to adopt these skills (Deci et al., 1989, Hardré and Reeve, 2009), but autonomy-supportive training has not been tailored to 
the learning needs of supervisors in low-skilled occupations. In fact, based on the review of a leadership programme by Garavan et al. (2015), most leadership programmes have not yet been tailored to the needs of supervisors in low-skilled occupations in terms of length and delivery method.

This article will describe the process of designing a programme for supervisors in lowskilled occupations to develop their supervisory skills. It first reviews the learning experience and opportunity of those in low-skilled occupations: understanding their learning experience and opportunities is beneficial for working towards the "how-to" of training for low-skilled occupations. It will then outline the development of the training programme and materials, demonstrating their basis in theoretical and andragogical models. Finally, preliminary evaluation of the training is reported on, through conducting pilot training for supervisors in low-skilled occupations.

\section{Learning experience and opportunity}

The term "low-skilled” generally refers to occupations with entry requirements of high school education or less and a year of working experience or less (Maxwell, 2006). In New Zealand, employees in low-skilled occupations can be defined as those in Skill level 4 and 5, which generally requires the completion of secondary education, though in some cases formal education can be compensated by on-the-job training (Australian Bureau of Statistics, 2013). As most low-skilled occupations require minimal education and work experience, they are frequently populated by those who are in a transitionary period of attaining higher education or have stopped high school although; there are also some who do not complete high school (Kluve et al., 2012, Maxwell, 2006). On the other hand, the role of supervisors is commonly 
taken up by those who have moved up the ranks from shop floor to supervisory role (Lowe, 1993, Hales, 2005). Supervisors in low-skilled occupations can be said to have similar educational experience and attainment as employees in low-skilled occupations based on the proposition by Hales (2005) and Lowe (1993) about supervisors being promoted from shop floor position. Therefore, training materials developed for the supervisors will need to cater to their educational level and experience.

One of the main considerations for supervisors in low-skilled occupations is the way they perceive training. Many in low-skilled occupations are hesitant to undertake education or training either consciously or unconsciously as the idea of returning to a similar situation which reminds them of their past experience of fear and rejection (Maxwell, 2006, Illeris, 2006). While recognising their struggles, many in low-skilled occupations also acknowledged the importance of upskilling for job security (Illeris, 2006) and personal and professional improvement (Colin, 2012). Hence, there is a sense of needing and wanting training but also conscious or unconscious reluctance to engage in training due to past experiences. Their previous struggle with formal education also means that training programmes for supervisors in low-skilled occupations need to consider designing the content and using methods beyond theoretical and classroom teaching to encourage participation in training.

In addition, supervisors face the challenge of lack of time to participate in training during work hours (Colin, 2012). The expectations of managing machines that are constantly running and providing ongoing service mean that supervisors are expected to be present at their work station during working hours (Rainbird, 2000), hence limiting their opportunity for training that occurs during this time. It is challenging for those in low-skilled occupations to engage in 
continuous learning if it is not supported by organizations, due to training fees and time cost (Colin, 2012). Organizations tend to be more motivated in offering leadership skills training if they are able to see the value of the training. Therefore, training programmes based on SDT, which has demonstrated the value of autonomy-supportive supervisory style, provides the theoretical foundation for the training programme for supervisors in low-skilled occupations.

Apart from the teaching of skills, autonomy-supportive supervisory style training also involves an examination of supervisors' beliefs and the principles of employee motivation (Reeve, 2006). Therefore, training content needs to incorporate strategies for supervisors to examine the beliefs and principles of their supervisory style. SDT research on autonomysupportive training, as well as Knowles et al. (2012) principles of adult learning, can be applied to the training programme to facilitate learning and application of an autonomy-supportive supervisory style. The section below reviews both theories in the context of developing an autonomy-supportive training programme for supervisors in low-skilled occupations.

\section{Continuous learning for supervisors in low-skilled occupations}

\section{SDT and autonomy-supportive style training}

According to SDT, an autonomy-supportive style is not just beneficial as a supervisory style but it can also facilitate self-determined learners through the fulfilment of basic psychological needs (Ryan and Deci, 2017). Self-determined learners or autonomous learners are those who initiate, regulate and approve their own actions based on the awareness of their needs, values and goals and do not feel compel to learn based on external pressures such as from trainers or managers (Reeve et al., 2003). When learners are self-determined, they are more 
engaged in learning, which then results in higher achievement of learning outcomes (Froiland and Worrell, 2016). Therefore, autonomy-supportive training could aim to create an autonomysupportive training environment, which will facilitate self-determined learners who would gain from the training.

The first autonomy-supportive training at work was conducted with managers of a large office machine corporation mainly through demonstrations, discussion and activities around three autonomy-supportive themes: (1) providing work-related choices to employees, (2) using non-controlling language to provide feedback, and (3) accepting and recognising employees’ needs and feelings (Deci et al., 1989). Following that, another workplace autonomy-supportive training study was conducted with managers in a multinational organization (Hardré and Reeve, 2009). This training used a combination of lectures, discussions and take-home guides as the method of delivery and focused on four autonomy-supportive themes: (1) nurturing employees' inner motivational resources, (2) relying on non-controlling language in communicating work standards and feedback, (3) providing rationales to communicate values of activities or procedures deemed uninteresting, and (4) acknowledging and accepting employees' negative affect when asked to perform difficult or unappealing tasks. Both the trainings resulted in managers using more autonomy-supportive skills and an increase in employees' trust and engagement in the organization.

The opposite of an autonomy-supportive style is the controlling supervisory style. The controlling supervisory style demands that employees adopt the supervisors’ perspective, interrupts employees' thoughts, feelings or actions and puts pressure on employees to think, feel and behave in certain ways. Such practice of control and command is not uncommon in the 


\section{lower-skilled occupations, especially in manufacturing industries (Ingvaldsen \& Benders}

2016), hence presenting a need to address the controlling supervisory style in the training. Hardré and Reeve (2009) recommended incorporating an awareness of the widespread nature of this controlling style into future autonomy-supportive training, encouraging learner to (1) become less controlling by being mindful of the reason they adopt a more controlling style and its consequences, (2) desire an autonomy-supportive supervisory style by helping them appreciate the benefit of it, and (3) learn how to practice autonomy-supportive practices.

Su and Reeve (2011) provided an additional guide on the design of autonomy-supportive training, by suggesting that trainers should: (1) conduct the training in only one or a few sessions for a moderate amount of time (i.e., within one to three hours), (2) offer follow-up activities or materials, (3) use a combination of instructional booklets and electronic media, (4) address pretraining beliefs about perceived effectiveness of the controlling style, especially with learners who are experienced in their field of work, and (5) focus on learning the four autonomysupportive behaviours, which are acknowledging negative affect, minimising the use of controlling language, providing a meaningful rationale, and nurturing inner motivational resources of employees.

Most of the recently reported autonomy-supportive trainings were conducted with higherskilled occupations such as teachers or clinicians, and included theoretical teaching of autonomysupportive and controlling styles. Although Su and Reeve (2011) mentioned that effective autonomy-supportive trainings focus on skills-based activities, many of these studies begin with an information session, where the instructor provides information about the theoretical background and strategy to autonomy-supportive behaviours. Discussions were normally 
incorporated into the training after the information session. This theoretical teaching of autonomy-supportive behaviour is unlikely to be appropriate for supervisors in low-skilled occupations. However, less is known about how to deliver the content to supervisors in lowskilled occupations in a way and in language they could relate to. Evidently, designing autonomy-supportive training for supervisors in low-skilled occupations requires support from other theoretical approaches such as andragogical principles to better cater to their training needs.

\section{Andragogy principles}

Knowles et al. (2012) suggest a few principles around adult learning which are crucial in understanding how adults learn best. These principles are: (1) adults need to understand the reason behind their learning: (2) adults need to be respected as self-directed individual learners; (3) adults accumulate experiences which are rich learning resources to tap into, and these should be given due attention; (4) adults learn when they are ready to learn; (5) there should be a focus on learning which helps adults to deal with tasks and problems; and (6) adults respond to internal motivation (i.e., increased job satisfaction and self-esteem) better than external motivation (i.e., pay rise, promotion) in learning. These principles of adult learning form the andragogical model, which is the process in which learners obtain skills and knowledge through procedures and resources provided by the instructor throughout the learning process.

In the andragogical model, a programme is designed by involving the learners and other relevant parties. Designing a programme based on a specific theoretical approach might sound counterintuitive to the andragogy principles, as it is likely not possible to involve a learner unfamiliar with the topic in the planning process of the training material. However, Knowles et 
al. (2012) assert that the effective application of andragogical principles requires balancing and adaptation of the principles depending on the situation and learners' characteristics. In a training programme based on a theoretical approach, there is a certain degree of content being determined by the facilitator, as learners might not be familiar with the topic yet. But ultimately, the aim of teaching should be directed towards developing learners' autonomy where learners engage in setting goals and aim to achieve their learning standards. This is in line with SDT’s aim to facilitate self-determination in learning. Therefore, the programme design should use a more self-directed training approach once the learners are familiar with the concept.

Though there are examples of andragogical principles being applied in management education (McCauley et al., 2017), such examples seem to be lacking in organizational training, especially for low-skilled occupations. Knowles et al. (2012) provided a case example of a workplace literacy programme for those lacking in basic literacy skills, though they do not give detail of how andragogical principles were applied to the design of the programme. Nevertheless, researchers such as Forrest III and Peterson (2006) frequently call for the application of andragogy as opposed to pedagogy (a more teacher-directed approach to training) in management education. Therefore, this study answers the call by applying andragogical principles to design a supervisory skills development training program for supervisors in lowskilled occupations.

The core of andragogical principles is the view of adult learners as self-directed learners, and this principle is in line with the autonomy-supportive approach to training. According to Ryan and Deci (2017), autonomy-supportive teachers act based on the principle that training should support development from within and not focus on merely providing information to the 
learners. Since both approaches have a similar assumption about the self-directedness of adult learners, integration of the andragogical approach in autonomy-supportive training means that the programme design will largely comprise the use of supervisors' experience and reflective training activities as compared to the traditional pedagogical approach of "teach and tell." As SDT forms the content of autonomy-supportive training, both SDT and andragogical principles can be applied to facilitate learning for adult learners. The following section will describe this integrated process of developing autonomy-supportive training for supervisors in low-skilled occupations.

\section{Design}

\section{Development of the autonomy-supportive training}

Autonomy-supportive training (AST) for supervisors in low-skilled occupations was designed based on SDT and andragogical principles. While the andragogical principles are consistent with SDT, the integration of andragogical principles into autonomy-supportive training requires planning that is beyond intuitive incorporation of the principles. Knowles et al. (2012) proposed using the whole-part-whole (WPW) model to systematically design a training programme. In this model, a training programme is firstly introduced as a unifying concept through clarification of the objectives, purpose and rationale of learning that learners can relate to. It is also about preparing the learners through motivating them to learn the concepts and skills that will be introduced. This process represents the first "whole." The "part" represents the specific skills to be taught in the programme, and finally the programme design concludes with integrating the individual skills learned within the overall theme of the programme. Following the integration, the programme will aim to help learners transfer such skills to their workplace. 
The integration of individual skills learned and the transfer of skills to the workplace represent the final "whole" of this model. Table 1 outlines the parallel concepts within the SDT and andragogical model along with the integration of both approaches into the design of our AST.

---Insert Table 1 here ---

As other ASTs, such as those conducted with teachers, used language and style that the teachers were familiar with, this programme has also been contextualized by using language and style suitable for low-skilled occupations in New Zealand. Workplaces in New Zealand are less formal than in much of the developed world (New Zealand Immigration, 2018). Therefore, AST uses colloquial language so that supervisors can relate to the training content and material. The programme design relies on discussion and use of relevant examples to facilitate learning, as such a method encourages learners to voice their perspective and learn from their experience. It is in line with both SDT and andragogical principles. The content is outlined below, in the order that AST is presented: preparing the learners, introducing autonomy-supportive skills, goal setting and peer support, and follow-up session.

\section{Preparing the learners}

The training programme begins by preparing the learners to learn about autonomysupportive skills. According to the WPW model, this functions as the first part of the "whole" where the objectives, purpose and concept of the training is introduced to the learners. The andragogical principles also assert that adults need to first understand the reason for their learning, and they learn when they are ready to learn. Similarly, Reeve (2009) proposed that prior to learning autonomy-supportive skills, learners need to understand why they use the 
controlling approach, the consequences of it and appreciate the benefit of the autonomysupportive style. In order to achieve this aim, participants were asked to reflect on the characteristics and consequences of having a good and bad boss to help them understand the consequences of having a bad boss and appreciate the benefit of having a good boss. The words "good boss" and "bad boss" were used to describe their managers, as participants were likely to be more familiar with the term good and bad instead of controlling and autonomy-supportive. The exercise is then used to bridge their experience with the learning objectives of AST. This helps learners to understand the reason for their learning, which will heighten their awareness of the need to learn autonomy-supportive skills.

\section{Introducing autonomy-supportive skills}

Autonomy-supportive trainings which begin with an information session, tend to explain the theory behind autonomy-supportive skills, present the empirical benefit for autonomysupportive teaching and finally explain autonomy-supportive strategies (Reeve and Cheon, 2014). This style of training is often associated with classroom learning in schools. As Illeris (2006) mentioned, school-like teaching would not be ideal for the low-skilled occupations due to their potentially estranged experience with school.

In this AST, the theoretical teaching was replaced by a presentation of relevant concrete examples of the four autonomy-supportive skills. The delivery of autonomy-supportive skills represents the "part" in the WPW model, where each autonomy-supportive skill along with examples of it was presented separately to the supervisors. The use of examples to demonstrate autonomy-supportive and controlling styles also means that supervisors can relate it to their real 
work experience, making it more relevant and less theoretical. Besides this, the examples demonstrated how autonomy-supportive skills can be practiced in their workplace.

For each autonomy-supportive skill, supervisors are given a short description of a scenario, followed by a continuum of responses through which they could approach the situation ranging from controlling to autonomy-supportive ways of handling the situation. Supervisors are encouraged to evaluate the responses and select what they perceive as autonomy-supportive and the reason they perceive the responses as autonomy-supportive. The reflection is followed by a group discussion that allows the supervisors to evaluate their beliefs in terms of which supervisory style they found effective and why. Reeve (2009) found that identifying the reason supervisors use a controlling or autonomy-supportive style helps them to be mindful of their supervisory style and become less controlling.

Following the reflection and discussion of examples, supervisors were asked to consider what they might find difficult about using the autonomy-supportive approach so they can discuss strategies to adapt the skills to their workplace. Other autonomy-supportive trainings have also included helping learners identify barriers and discussing application of these skills to their workplace (Cheon and Reeve, 2015, Hardré and Reeve, 2009).

After the introduction of autonomy-supportive skills, supervisors were given the opportunity to apply and practice the skills. One of the important aspects of autonomy-supportive training is the opportunity to learn how to use the skills at their workplace (Su and Reeve, 2011). Supervisors are given an employee management scenario that they are likely to encounter in their role and were asked to discuss with each other the controlling, moderately autonomy-supportive and autonomy-supportive responses to the situation. The moderately autonomy-supportive option 
gives the supervisors the choice to move towards an autonomy-supportive supervisory style, especially for more controlling supervisors who might perceive changing from controlling to autonomy-supportive as unrealistic. Reeve (2009) mentioned that learners might resist the autonomy-supportive approach if they perceived it as unrealistic given the challenges they may face in their workplace.

Following the discussion, supervisors were encouraged to use either the scenario discussed or a more recent and relevant situation to practice the autonomy-supportive responses with each other. According to andragogical principles, adults are motivated to learn when the skills they are learning are helpful in solving their current problem. Apart from that, the practice session helps learners to familiarise themselves with the skills and build confidence in using them. Although this section introduced specific skills that are the "part," it also incorporates the second "whole" in the WPW model by encouraging supervisors to practice the overall autonomy-supportive skills in order to facilitate mastery of the skills.

\section{Goal setting and peer support}

The programme content ends with goal setting and sharing the goals with their peers for support and to encourage transfer of training to the workplace. It is also the continuation of the second "whole” from the practice session. Supervisors were encouraged to set their own goals in practicing an autonomy-supportive supervisory style at their workplace. Setting their own goal is in line with the andragogical principles of respecting the needs of self-directed learners. It also fulfils the autonomy need of supervisors, as they are given the opportunity to reflect on how they can apply autonomy-supportive supervisory style in their workplace. Finally, supervisors were encouraged to share their goals with their peers as a support in their use of autonomy-supportive 
skills. Participants who receive support from the organization, supervisors and peers and also participated in peer support networks reported a higher level of transfer in training knowledge and skills (Cromwell and Kolb, 2004, Wei Tian et al., 2016).

\section{Follow-up session}

A follow-up session was incorporated into the training programme, two weeks after the initial training. In the follow-up session, supervisors engaged in group discussions of their actual experience in practicing autonomy-supportive supervisory style. They were encouraged to discuss experiences, concerns and obstacles, and ways to improve the strategies of practicing an autonomy-supportive supervisory style. The discussion topics were adapted from the autonomysupportive training by Cheon et al. (2012). AST moves from using prescribed content to discussion of experience and developing strategies for the autonomy-supportive supervisory style which suits their context. This section encourages greater autonomy in learning as supervisors discuss with each other the application of autonomy-supportive practices in their workplace.

Overall, the AST incorporates SDT and andragogical principles to develop a training programme tailored to the specific needs and requirements of supervisors in low-skilled occupations. The following section describes the process and findings of the preliminary evaluation of AST with the supervisors. 


\section{Methodology}

\section{Preliminary evaluation of AST}

An invitation for supervisors to participate in and evaluate AST was extended to human resource personnel or general manager of manufacturing, hospitality and retail service organisations in New Zealand. Two organisations, one a manufacturing and the other a cleaning service responded with support for the study. The training sessions were held in each participating organisation and conducted by the first author. A total of 11 supervisors participated in the preliminary training, three from the manufacturing sector and eight from the cleaning service industry. Participants were informed at the beginning that the training programme comprised part of a larger autonomy-supportive supervisory style study, and that their feedback about the training content and design would be used to guide improvements in the AST. Given the limited number of participants and in order to reassure participants that their responses would be anonymous, demographic information was not collected.

Kirkpatrick and Kirkpatrick (2006) assert the importance of evaluating the reaction of learners, as such evaluation provides valuable information about the programme for reporting to stakeholders, allows participants to offer suggestions about improvements, and helps to establish standards of performance for trainers in future programmes. While it is important to evaluate the learning (Level 2), behaviour (Level 3) and results (Level 4) of AST, the reaction evaluation plays an important role as the first step of evaluation in AST. This is because AST has been newly adapted for supervisors in low-skilled occupations, and feedback on how the programme is received by this category of learners will help to make improvements to AST prior to implementing more complex and time-consuming higher-level evaluations. 
At the end of the session, a feedback form was distributed and collected the same day by the first author. An open-ended structured questionnaire consisting of seven open-ended questions was used to collect data, gauging learners' satisfaction with AST content in terms of relevance, ease of understanding, delivery method, the topic arrangement and its effectiveness in prompting supervisors to use the skills. Learners were encouraged to include written comments and suggestions so that the reasons for their reactions and what could be done to improve the programme would become known. Such evaluation is in line with the andragogical principle of respecting adults as self-directed learners who understand their learning needs. It is also taking consideration of the supervisors' perspectives, which is one of the key principles of the autonomy-supportive training environment. An example of questions that asked about the content was: At the end of the workshop, do you think that the content is reasonably applicable to your workplace? Why?

Data were analysed using a structured approach to thematic analysis where conceptualising of themes are based on domains such as questions asked in the interview (Braun et al., 2019). Therefore, in this study, themes were determined, codes were identified, and results presented according to questions asked in the feedback form. In addition to the feedback collected from participants, the trainer engaged in critical reflection on the experience of conducting the training. The following sections report on these reflections and a detailed evaluation of the training. 


\section{Findings}

\section{Trainer's reflection}

One of the key criteria for AST to be successful is providing an autonomy-supportive training environment to the learners. The facilitator involved in autonomy-supportive training needs to understand the autonomy-supportive style and the benefit of it to be able to not just deliver the content but practice what they intend to deliver in the training session. During the training session, the first author was able to use autonomy-supportive skills such as acknowledging and accepting negative affect of supervisors when supervisors shared their concerns and struggles in using autonomy-supportive skills with certain types of employees. The issues raised by the supervisors were reflected and opinions were solicited from others in the group on how they would handle the issue in an autonomy-supportive style. Those who were not directly involved in the issues provided suggestions and feedback on the issues during the discussion. Such a facilitation method assumes that supervisors are self-directed learners, capable of finding solutions to their issues when given the resources, such as information on autonomy-supportive skills and an autonomy-supportive training environment.

Autonomy-supportive skills were delivered in discussion style through scenarios and examples as outlined in the design of AST. After each discussion, the rationale and benefit of using each skill were reiterated and explained to the supervisors. By providing a meaningful rationale of autonomy-supportive skills to the supervisors, it was easier for the supervisors to accept the autonomy-supportive message. Finally, it seems that many supervisors held strong controlling beliefs that employees need to be told what to do. Instead of using the controlling way to tell supervisors what they should do or avoid doing, discussion was used for supervisors 
to evaluate the effectiveness of their supervisory style. Following the discussion, a rationale of the detrimental effects of controlling practices and benefits of autonomy-supportive practices was provided for supervisors so they could consider the benefits of adopting an autonomysupportive supervisory style and avoiding controlling practices. Through using autonomysupportive skills in facilitating the training session, supervisors felt their opinion and experience matters. They were also able to discuss strategy using autonomy-supportive skills to find solutions to their current issues.

A challenge encountered in the programme design was getting supervisors to set goals to practice the autonomy-supportive supervisory style. The goal setting section was designed with some basic guides for supervisors to specify an action they would take to practice the autonomysupportive style as well as when and how they planned to execute it. Supervisors could decide on their own goal based on the guide provided in the booklet. As no example was given, supervisors struggled to specify actions related to the autonomy-supportive supervisory style. The supervisors were generally unfamiliar with goal setting method. However, when supervisors were given further guidance, such as an example, they were better able to grasp the idea of how to state details of an action plan as their goal. Following this, an example of autonomysupportive supervisory style was added to the goal-setting section in the booklet as a reference for supervisors.

\section{Evaluation outcomes and discussion}

Out of the 11 supervisors, 10 felt the programme was reasonably applicable to their workplace, as it helped them to reflect and improve on their communication and relationship with the employees. One supervisor did not respond to the question. 
Yes, it is applicable, because it makes everyone reflect and think about how they communicate with others (B3).

Yes, it helps to eliminate tension amongst staff (U8).

All 11 participants felt the content was delivered effectively through the use of relevant examples, discussions, scenarios and, practice sessions.

Used examples that we could relate to (B1).

Yes, discussion is a key component of delivering information allowing more people at understanding in a variety to perspectives (B2).

Most supervisors also felt that the training made them think about how to practice the autonomy-supportive supervisory style by using less negative and more positive language, and a few supervisors mentioned it was a reminder for them to use a more autonomy-supportive approach.

It is a reminder of the value of supportive supervising (B2).

Use more positive words (U7).

In general, supervisors found the content and discussion questions easy to understand. However, there was a discussion question around what might "block" them from practicing an autonomy-supportive approach, which they felt needed clarification. They offered suggestions to change the word "block" to "stop.” The participants also felt the topics were well-arranged, with some mentioning it was well-arranged because it is related to their workplace and others 
mentioning the arrangement of topics was from general to specific to their situation. The conclusion and future research in relation to AST will be discussed.

\section{Conclusion and future research}

This paper reports on the development of an autonomy-supportive training programme, which is theoretically grounded in SDT and delivered in a way that supervisors in low-skilled occupations can understand and relate to. SDT and andragogical principles were integrated systematically into the programme so that supervisors could learn autonomy-supportive skills through reflection, discussion of experience and practicing the skills with each other. Preliminary evaluation of AST with 11 supervisors found the programme was designed appropriately, easy to understand and relevant to their workplace. Participants found the method of delivery, which used examples, scenarios, discussions and practice sessions, was helpful in learning AST. To our knowledge, this is the first AST to integrate SDT with andragogical principles of adult learning to develop a much-needed training programme for supervisors in low-skilled occupations.

Although the preliminary evaluation consists of only reaction level responses from participants combined with the trainer's critical reflections, it provides the basis for making necessary improvements to AST. Further research is needed to assess AST at higher levels of evaluation in order to provide more information on how AST could change supervisory styles and its potential organizational outcomes. An experimental or quasi-experimental design could provide insight to the effect of AST on supervisors, employees and organisations. Future studies involving training of supervisors in low-skilled occupations should consider systematically integrating relevant and compatible theories as shown in this article as well as take into account the previous learning experiences to maximise learning. 
In conclusion, the outcome of the preliminary evaluation does demonstrate that AST is appropriate for and can be used with supervisors in low-skilled occupations, opening up the benefits of an autonomy-supportive style to employees in these traditionally neglected roles. 


\section{References}

Australian Bureau of Statistics. (2013). “Australian and New Zealand Standard Classification of Occupations Version 1.2”, available at https://www.abs.gov.au/ausstats/abs@.nsf/Lookup/1220.0Chapter22013,\%20Version\%2 01.2 (accessed 15 January 2019).

Braun, V., Clarke, V., Hayfield, N. \& Terry, G. (2019). “Thematic analysis”. In: Liamputtong, P. (ed.) Handbook of Research Methods in Health Social Sciences. Springer Nature Singapore Pte Ltd., Singapore, pp. 843-860.

Cheon, S. H., Moon, I. S. \& Reeve, J. (2012). "Experimentally based, longitudinally designed, teacher-focused intervention to help physical education teachers be more autonomy supportive toward their students", Journal of Sport and Exercise Psychology, Vol.34 No.3, pp. 365-396.

Cheon, S. H. \& Reeve, J. (2015). "A classroom-based intervention to help teachers decrease students’amotivation", Contemporary Educational Psychology, Vol.40, pp. 99-111.

Colin, L. (2012). Engaging Low Skilled Employees in Workplace Learning. Evidence Report 43, London UK Commission for Employment and Skills, London, UK.

Cromwell, S. E. \& Kolb, J. A. (2004). "An examination of work - environment support factors affecting transfer of supervisory skills training to the workplace", Human Resource Development Quarterly, Vol.15 No.4, pp. 449-471.

Deci, E. L., Connell, J. P. \& Ryan, R. M. (1989). "Self-determination in a work organization", Journal of Applied Psychology, Vol.74 No.4, pp. 580-590.

Deci, E. L., Olafsen, A. H. \& Ryan, R. M. (2017). "Self-determination theory in work organizations: The state of a science”, Annual Review of Organizational Psychology and Organizational Behavior, Vol.4 No.1, pp. 19-43.

Forrest III, S. P. \& Peterson, T. O. (2006). "It's called andragogy", Academy of Management Learning \& Education, Vol.5 No.1, pp. 113-122.

Froiland, J. M. \& Worrell, F. C. (2016). "Intrinsic motivation, learning goals, engagement, and achievement in a diverse high school", Psychology in the Schools, Vol.53 No.3, pp. 321336.

Garavan, T., O'brien, F. \& Watson, S. (2015). "Leadership development and organizational success", in Kraiger, K., Passmore, J., Santos, N. R. D. \& Malvezzi, S. (ed.), The Wiley Blackwell Handbook of the Psychology of Training, Development, and Performance Improvement, John Wiley \& Sons Ltd., West Susex, UK, pp. 354-397. 
Green, R., Agarwal, R., Brown, P., Tan, H. \& Randhawa, K. (2011). "Management Matters in New Zealand: How Does Manufacturing Measure Up?", Occasional Paper, available: http://www.mbie.govt.nz/publications-research/publications/economicdevelopment/2011-occasional-papers/Management-matters-in-NZ-11-03.pdf. (accessed 10 December 2018)

Hales, C. (2005). "Rooted in supervision, branching into management: Continuity and change in the role of first - line manager", Journal of Management Studies, Vol.42 No.3, pp. 471506.

Hardré, P. L. \& Reeve, J. (2009). "Training corporate managers to adopt a more autonomysupportive motivating style toward employees: An intervention study", International Journal of Training and Development, Vol.13 No.3, pp. 165-184.

Illeris, K. (2006). "Lifelong learning and the low - skilled", International Journal of Lifelong Education, Vol.25 No.1, pp. 15-28.

Ingvaldsen, J. A. \& Benders, J. (2016), "Lost in translation? The role of supervisors in lean production”, German Journal of Human Resource Management, vol. 30, no. 1, pp. 35-52.

Kirkpatrick, D. L. \& Kirkpatrick, J. D. (2006). Evaluating Training Programs: The Four Levels, Berrett-Koehler Publishers, Inc., San Francisco, CA.

Kluve, J., Rother, F. \& Puerta, M. L. S. (2012). "Training programs for the unemployed, lowincome, and low-skilled workers", in Almeida, R., Behrman, J. \& Robalino, D. (ed.), The Right Skills for the Job? Rethinking Training Policies for Workers, World Bank, Washington, DC, pp. 116-145.

Knowles, M. S., Holton, E. F. \& Swanson, R. A. (2012). The adult learner: The definitive classic in adult education and human resrouce development, Routledge, New York, NY.

Kyndt, E., Govaerts, N., Keunen, L. \& Dochy, F. (2013). "Examining the learning intentions of low-qualified employees: A mixed method study", Journal of Workplace Learning, Vol.25 No.3, pp. 178-197.

Lawrence, J. (2013). "Lack of support for managers leads to leadership problems and crisis of organisational culture”. HRZone, available: http://www.hrzone.com/lead/change/lackof-support-for-managers-leads-to-leadership-problems-and-crisis-of-organisational (accessed 3 January 2019).

Lowe, J. (1993). "Manufacturing reform and the changing role of the production supervisor: The case of the automobile industry", Journal of Management Studies, Vol.30 No.5, pp. 739758.

Maxwell, N. L. (2006). The Working Life: The Labor Market for Workers in Low-Skilled Jobs, WE Upjohn Institute for Employment Research, Kalamazoo, MI. 
Mccauley, K. D., Hammer, E. \& Hinojosa, A. S. (2017). "An andragogical approach to teaching leadership", Management Teaching Review, Vol.2 No.4, pp. 312-324.

New Zealand Immigration. (2018). “Guide to Kiwi Workplaces”, available: https://www.newzealandnow.govt.nz/work-in-nz/nz-way-of-working (accessed 13 November 2018).

Payne, J. (2006). "The Norwegian competence reform and the limits of lifelong learning", International Journal of Lifelong Education, Vol.25 No.5, pp. 477-505.

Pederson, L. S., Dresdow, S. \& Benson, J. (2013). "Significant tasks in training of job-shop supervisors", Journal of Workplace Learning, Vol.25 No.1, pp. 23-36.

Purcell, J. \& Hutchinson, S. (2006). "Front-line managers as agents in the HRM-performance causal chain: Theory, analysis and evidence", Human Resource Management Journal, Vol.17 No.1, pp. 3-20.

Rainbird, H. (2000). "Skilling the unskilled: Access to work-based learning and the lifelong learning agenda", Journal of Education and Work, Vol.13 No.2, pp. 183-197.

Reeve, J. (2006). "Teachers as facilitators: What autonomy-supportive teachers do and why their students benefit", The Elementary School Journal, Vol.106 No.3, pp. 225-236.

Reeve, J. (2009). "Why teachers adopt a controlling motivating style toward students and how they can become more autonomy supportive", Educational Psychologist, Vol.44 No.3, pp. 159-175.

Reeve, J. \& Cheon, S. H. (2014). "An intervention-based program of research on teachers' motivating styles", in Karabenick, S. A. \& Urdan, T. C. (ed.), Advances in Motivation and Achievement, Emerald Group Publishing Limited, Bingley, United Kingdom, pp. 293-339.

Reeve, J., Nix, G. \& Hamm, D. (2003). "Testing models of the experience of self-determination in intrinsic motivation and the conundrum of choice", Journal of Educational Psychology, Vol.95 No.2, pp. 375-392.

Ryan, R. M. \& Deci, E. L. (2017). Self-Determination Theory: Basic Psychological Needs in Motivation, Development, and Wellness, Guilford Publications, New York, NY.

Slemp, G. R., Kern, M. L., Patrick, K. J. \& Ryan, R. M. (2018). "Leader autonomy support in the workplace: A meta-analytic review", Motivation and Emotion, Vol.42 No.5, pp. 706-724.

Su, Y.-L. \& Reeve, J. (2011). "A meta-analysis of the effectiveness of intervention programs designed to support autonomy", Educational Psychology Review, Vol.23 No.1, pp. 159188. 
Teague, P. \& Roche, W. K. (2012). "Line managers and the management of workplace conflict: Evidence from Ireland", Human Resource Management Journal, Vol.22 No.3, pp. 235251.

Wei Tian, A., Cordery, J. \& Gamble, J. (2016). "Returning the favor: Positive employee responses to supervisor and peer support for training transfer", International Journal of Training and Development, Vol.20 No.1, pp. 1-16. 